\title{
Tribological Characteries of DLC film in Sliding Contacts under Different Lubrication Conditions
}

\author{
Y.Bai ${ }^{1}$ P. $\mathrm{CaO}^{2}$ \\ ${ }^{1}$ Changchun Institute of Optics, Fine Mechanics and Physics, Chinese Academy of Sciences, \\ Changchun, China \\ ${ }^{2}$ Changchun Institute of Technology, Changchun, China
}

KEYWORD: Mixed film lubrication; DLC; friction; wear

ABSTRACT: Diamond-like carbon (DLC) films are well known for their high hardness, low friction and excellent wear resistance. Therefore, DLC film coating can contribute to improving mechanical and tribological properties of materials. The objective of this study is to investigate the effect of solid and liquid lubrication on friction and wear performance of selected solid lubricating coatings, comparative experiments have been carried out on chemical vapor deposited hydrogenated diamond-like carbon (DLC) films against Si3N4 ball, using a ball-on-disk tribo-tester under the conditions of room temperature and different lubrication conditions. Surface morphology of coatings were investigated by atom force microscope (AFM), friction coefficient (COF) and wear rate of solid films be analyzed also. It was shown that the friction be greatly reduced when the solid film lubricated with oil and grease simultaneously compared to lubricated singly at the start-up or under boundary lubrication conditions. The effect of lubrication oil to the wear resistance property of MoS2 DLC was better than lubrication grease.

\section{INTRODUCTION}

In industrial design, friction and wear volume affect productivity and machine lifetime directly.

As competition increases in the global economy, more attention has dedicated to understanding the physics and chemistry of moving part and to finding advanced lubricants. Diamond-like carbon (DLC) coatings are nowadays used in many applications with aim of reducing friction and wear. The main reason for their use is the well-known intrinsic characteristics of DLC films, namely high hardness and low surface roughness, affording low friction volume and low wear rate [1-5].

Most of the traditional Solid lubricants have been used successfully in various engineering applications when liquid lubricants do not meet the advanced requirements of modern technology [6,7], and the present state of the art in solid lubricant coatings has reached a point where they can now be produced on all kinds of tribological surfaces at thickness ranging from a few nanometers to several micrometers [8].

Well-known examples are molybdenum disulfide, graphite, diamond and diamond-like carbon, etc. $\mathrm{MoS}_{2}$ thin film differ from graphite mainly in that its low friction is an inherent property and does not depend on the presence of adsorbed vapors, and it have been widely used as solid lubricants in both high vacuum and dry environment conditions than any other lubricating solid $[9,10]$. Diamond-like carbon (DLC) films are of great interest as a protective coating in industrial tools and medical implants due to the low coefficients of friction and low wear rates [11,12], and Diamond-like carbon film has some perfect properties simultaneous with diamond, such as excellent chemical stability, high hardness, high elastic modulus and better wear resistance properties, etc.

Many factors or conditions also affect sold lubricant performance: type of substrate material, type of counter-face material, contact stress, temperature, sliding speed, and environment, etc [8, 9]. When surfaces run together under thin film conditions, enough oil is often present so that part of the load is carried by fluid films and part is carried by contact between the surfaces, and the effect of oil to the performance of solid coatings is not clearly yet [8].

To achieve better lubricity in demanding tribological applications, more and more attention be paid on solid lubrication coatings used with liquid lubricants simultaneously in recent two decades [14-17], but knowledge of the tribological performance of the coatings in lubricated conditions is still quite limited. 
In this study, the authors present some results of tribological investigations of coated elements lubricated with various types of liquid lubricants in view of compound mechanism of liquids and coatings. Comparative experiments have been carried out on magnetron sputtered $\mathrm{MoS}_{2}$ films and chemical vapor deposited DLC coatings against $\mathrm{Si}_{3} \mathrm{~N}_{4}$ ball using a ball-on-disk tribo-tester under the conditions of room temperature and different lubrication condition. Surface morphology of coatings were investigated by atom force microscope (AFM), friction coefficient (COF) and wear rate of solid films be analyzed also.

\section{EXperiment set-up}

Three Kinds of standard single thin coatings were prepared by state key laboratory of solid lubrication in Lanzhou institute of chemical physics, it is chemical-vapor-deposited diamond-like carbon (DLC) coating. The properties of investigated coatings are summarized in Table 1.

Table 1

Characteristics of invested solid lubrication films

\begin{tabular}{lc}
\hline Film & CVD DLC \\
\hline Material & Carbon \\
Thickness, $\mu \mathrm{m}$ & $0.2 \pm 0.02$ \\
Mean surface rough- & 29.2 \\
ness(Ra) ,nm & $\geq 40$ \\
Critical load,N & $\geq 5$ \\
Carrying capacity,GPa & \\
\hline
\end{tabular}

The liquid lubricants used in the experiments on solid lubrication films-liquid lubricants composite lubrication were synthetic oil and grease, both were commercial supplied and possess excellent lubricity. The synthetic oil was aviation precise instrument oil (4122), produced in China. The kinematic viscosity of lubricating base oil at $40^{\circ} \mathrm{C}$ and $100{ }^{\circ} \mathrm{C}$ are $42 \mathrm{~mm}^{2} \cdot \mathrm{s}^{-1}$ and $14.48 \mathrm{~mm}^{2} . \mathrm{s}^{-1}$, respectively. The lubricant grease was rolling bearing grease L252 (KE2G-40), made in Germany. Base oil is synthetic ester and the complex thickener is lithium soap, the kinematic viscosity is $150 \mathrm{~mm}^{2} \cdot \mathrm{s}^{-1}$ at $100{ }^{\circ} \mathrm{C}$.

The tribological experiments were carried out using a ball-on-disk tribometer(Figure 1) in air and at room temperature. $\mathrm{A} \mathrm{Si}_{3} \mathrm{~N}_{4}$ ball having $6 \mathrm{~mm}$ in diameter loaded $6 \mathrm{~N}$ slide with a steel disk coated with single solid lubrication film under difference lubrication, and the mean surface roughness $(\mathrm{Ra})$ of the ball having $75 \sim 80 \mathrm{HRC}$ in rigidity value was baout $0.014 \mu \mathrm{m}$. The opposite of contacts is a steel disk, made from $9 \mathrm{Cr} 18$, with $60 \sim 65 \mathrm{HRC}$ degree of hardness.

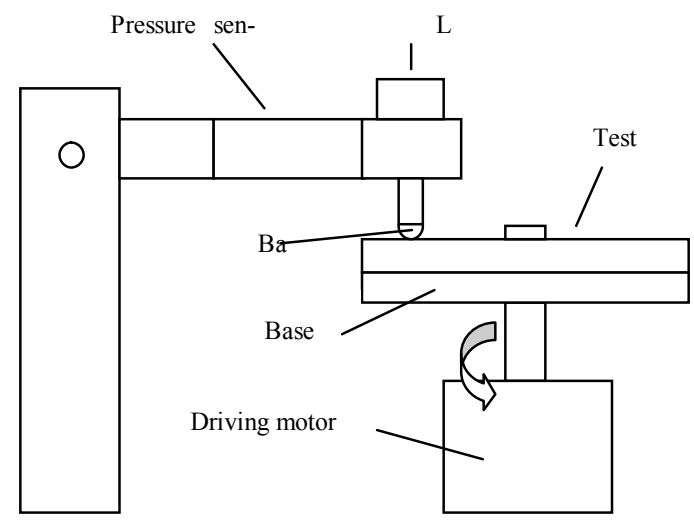

Figure 1. Test system of tribological experiments

The friction between the contact surfaces detected by a pressure transducer, and the coefficient varying with the change of the speed of disk from 0 to $1000 \mathrm{rpm}$ described the effect of mixed-films lubrication.

Test conditions of wear experiments on the thin films were $6 \mathrm{~N}$ load and $500 \mathrm{rpm}$ with the liquid lubricants or not. Following each test, the wear volume of the film was determined by measuring the wear scars, which be detected and analyzed using atomic force microscopy (AFM). 


\section{results and discussion}

The coefficient of friction of DLC coating sliding against a $\mathrm{Si}_{3} \mathrm{~N}_{4}$ ball under a load of $4 \mathrm{~N}$ in different environments is pressed in Figure 2.

The tribological response of lubricants to the friction of DLC thin films at start-up showed that the friction between the ball and the disk were reduced when lubricated with oil, and that had the lowest when lubricated grease. The value of friction of DLC film between the film and the contacting surface reduced from 0.199 to 0.187 when lubricated with oil, and the coefficient of friction decreased further more to 0.17 when grease was used as lubricants.

It is clear, the friction coefficient of DLC film when the oil or grease used as lubricant were much lower than that lubricated with solid film singly at every test speed, but the difference between that lubricated with oils and grease is relatively small at low speeds. When the speed arrived at $2000 \mathrm{rpm}$, the effects of that used oils was better than grease, which brought a great fall of the friction. Additionally, the friction coefficient of the DLC film descended gradually with the rising of sliding speed when lubricants were used or not.

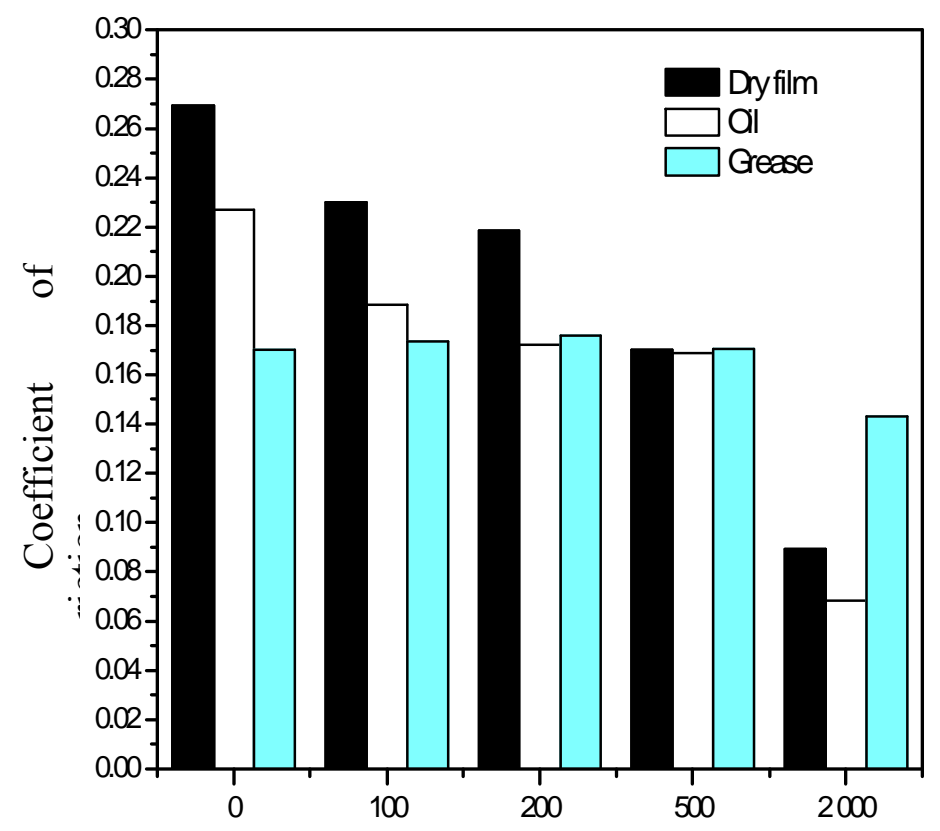

Speed of DLC film sliding against ball

Figure 2. Coefficient of friction of DLC films under different lubrication.

Surface morphology and wear tracks of the samples after the wear tests were investigated aby using atom force microscope (AFM). Figure 3 shows the microstructural characterization of DLC film that has experienced sliding wear tests. In this experiment, the thickness of chemical vapor deposited DLC film was about $0.2 \mu \mathrm{m}$. For all that, the difference of the surface profiles was clear yet, The surface of dry film was better than that when Oil was used which similar to $\mathrm{MoS}_{2}$ coating, the grooves on dry film were not deeper as that obtained under oil lubrication, and the contact area lubricated with grease was flattest. There has been a significant difference between the roughness values which reflected the morphology on the surface obtained after the tribological experiment on the film under three different lubrication conditions, which reflected the difference on the wear surface. Figure 5 also show the surface properties of DLC films, the mean surface roughness values (Ra) of chemical vapor deposited DLC films when tested on the dry film and with grease and oil were $23.1 \mathrm{~nm}, 12.5$ $\mathrm{nm}$ and $46.7 \mathrm{~nm}$, respectively. 
(a)

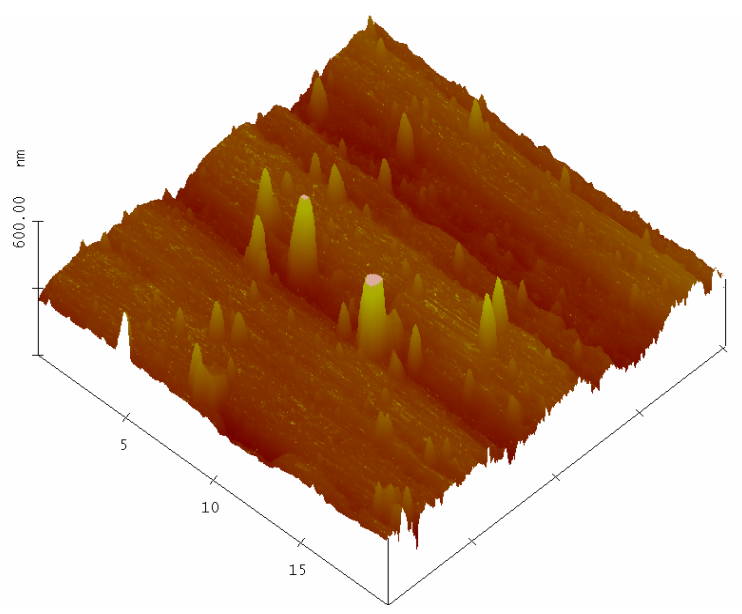

(b)

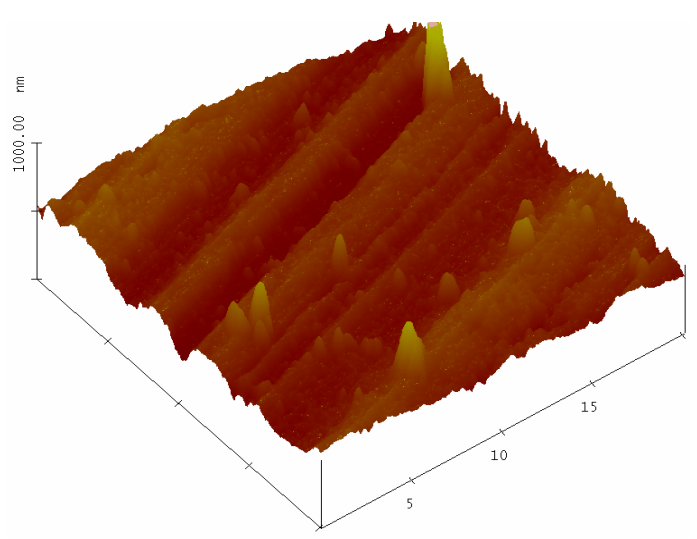

(c)

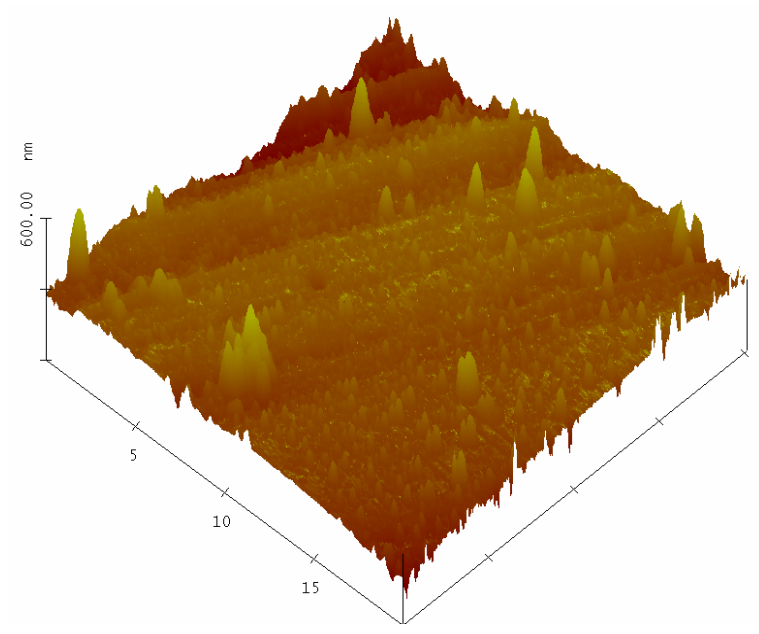

Figure 3. The surface topography and characteristics of DLC film after experiment under different lubrication. (a) dry, (b)4122, (c)L252 


\section{Conclusions}

In this study, Pin-on disc tests of DLC film coating sliding against in air under different tribo-test conditions were carried out, and the properties of combining a liquid (oil/grease) lubricant and a solid-lubricant film are summarized as follows:

The tribological response of liquid lubricant to the friction of DLC solid-lubricant films at start-up showed that the friction between the ball and the disk were both reduced when lubricated with oil, and that had the lowest when lubricated grease. When the mutual surfaces come into boundary lubrication, the friction of the solid film lubricated with oil and grease simultaneously was greatly reduced than dry film.

The wear resistance property of chemical vapor deposited DLC coatings expressed different effect under different lubrication condition. The experiment results show that liquid lubrication causes a dramatic decrease of the DLC coatings.

\section{ACKNOWLEDGEMENTS}

This work is supported by National Natural Science Foundation of China under Grant No.50905174, No.11372309 and No. 61304017, the Natural Science Foundation of Ji Lin province under Grant No.20101530, No. 20150204074GX and No. 201101090, and the Industrialization project of Ji Lin province under Grant No.2014SYHZ0004, and STS project of Chinese Academy of Science under Grant No.KFJ-EW-STS-068.

\section{REFERENCES}

[1] J. Robertson. Materials science and engineering 2002; 7:29-38.

[2] Podgornik B, Jacobson S, Hogmark S. Tribiology international 2003;36:843-9.

[3] Hauert R.. Tribology international 2004; 37:991-1003.

[4] Dearnaley G, Arps JH. Surface coating technology 2005;200:2518-24.

[5] J.R. Gomes, S. S. Camargo Jr., R.A. Simao, J.M. Carrapichano, C.A. Achete, R.F. Silva. Vacuum 2007; 81:1448-52.

[6] Kazuhisa Miyoshi. Solid lubrication fundamentals and applications/ friction and wear properties of selected solid lubricating films: case studies. NASA TM-107249( 2000)

[7] William R. Jones Jr, Mark J. Jansen. Lubrication for space applications. NASA CR213424(2005).-

[8] Erdemir A. Review of engineered tribological interfaces for improved boundary lubrication. Tribology International. 2005;38:249-256.

[9] Hilton M R, Fleischauer P D. Applications of solid lubricant films in spacecraft. Surface and Coatings Technology, 1992;54/55:435-441.

[10] Talivaldis Spalvins. Morphological and frictional behavior of sputtered $\mathrm{MoS}_{2}$ films. Thin Solid Films, 1982; 96:17-24

[11] Heon Woong Choi, David M. Gage, Reinhold H, et al. Effects of thermal annealing and Si incorporation on bonding structure and fracture properties of diamond-like carbon films. Diamond \& Related Materials. 2009; 18: 615-619.

[12] Kim H G, Ahn S H, Kim J G, et al. Effect of Si-incorporation on wear-corrosion properties of diamond- like carbon films. Thin Solid Films. 2005;482: 299-304

[13] Robert L. Fusaro. Lubrication of space systems. NASA-TM -106392(1994.)

[14] Tagawa M, Yokota K, Matsumoto K, et al. Space environmental effects on $\mathrm{MoS}_{2}$ and diamond-like carbon lubricating films: Atomic oxygen-induced erosion and its effect on tribological properties. Surf Coat Technol. 2007,202: 1003-1010.

[15] Erdemir A, Erck R A, Fenske G R, et al. Solid/liquid lubrication of ceramics at elevated temperature. Wear 1997,203-204:588-595.

[16] Erdemir A, Ajayi O O, Fenske G R, et al. Synergistic effects of solid and liquid lubrication on the tribological behavior of transformation-toughened $\mathrm{ZrO}_{2}$ ceramics. Tribol Trans 1992,35(2):287297.

[17] Remigiusz Michalczewshi, Witold Piekoszewski, Marian Szczerek, et al. The lubricantcoating interaction in rolling and sliding contacts. Tribology International. 2009; 42:554-560. 